\title{
Analysis by confocal laser scanning microscopy of the MDPB bactericidal effect on S. mutans biofilm CLSM analysis of MDPB bactericidal effect on biofilm
}

\author{
Fabíola Galbiatti de CARVALHO', Regina Maria PUPPIN-RONTANI', Suzana Beatriz Portugal de $\mathrm{FÚCIO}^{3}$, Thais de \\ Cássia NEGRINI ${ }^{4}$, Hugo Lemes CARLO ${ }^{5}$, Franklin GARCIA-GODOY ${ }^{6}$
}

\begin{abstract}
1- DDS, MSc, PhD Professor, Health and Technology Rural Center, Federal University of Campina Grande, Patos, PB, Brazil.
2- DDS, MSc, PhD Professor, Department of Pediatric Dentistry, School of Dentistry of Piracicaba, State University of Campinas, Piracicaba, SP, Brazil.

3- DDS, MSc, PhD student, Department of Restorative Dentistry, Dental Materials Area, School of Dentistry of Piracicaba, State University of Campinas, Piracicaba, SP, Brazil.

4- DDS, MSc, PhD student, Department of Microbiology, School of Dentistry of Piracicaba, State University of Campinas, Piracicaba, SP, Brazil. 5- DDS, MSc, PhD Professor, Department of Operative Dentistry, Health Science Center, Federal University of Paraíba, João Pessoa, PB, Brazil. 6- DDS, MSc, Professor and Senior Executive Associate Dean for Research and Director, Bioscience Research Center, College of Dentistry, University of Tennessee, Memphis, TN, USA.
\end{abstract}

Corresponding address: Profa. Dra. Fabíola Galbiatti de Carvalho - Curso de Odontologia - Centro de Saúde e Tecnologia Rural - Universidade Federal de Campina Grande - Av. Universitária s/n - Santa Cecília - Patos - PB - 58708-110 - Phone +55-83-3511-3064 - Fax: +55-83-3511-3009 - e-mail: fabigalbi@ yahoo.com.br

Received: April 11, 2012 - Modification: August 21, 2012 - Accepted: September 14, 2012

\section{ABSTRACT}

ince bacteria remain in the dentin following caries removal, restorative materials with $\checkmark$ antibacterial properties are desirable to help maintaining the residual microorganisms inactive. The adhesive system Clearfil Protect Bond (PB) contains the antibacterial monomer 12-methacryloyloxydodecylpyridinium bromide (MDPB) in its primer, which has shown antimicrobial activity. However, its bactericidal effect against biofilm on the dentin has been little investigated. Objective: The aim of this study was to analyze by confocal laser scanning microscopy (CLSM) and viable bacteria counting (CFU) the MDPB bactericidal effect against $S$. mutans biofilm on the dentin surface. Material and Methods: Bovine dentin surfaces were obtained and subjected to $S$. mutans biofilm formation in BHI broth supplemented with $1 \%(\mathrm{w} / \mathrm{v})$ sucrose for $18 \mathrm{~h}$. Samples were divided into three groups, according to the primer application $(n=3)$ : Clearfil Protect Bond $(P B)$, Clearfil SE Bond, which does not contain MDPB, (SE) and saline (control group). After the biofilm formation, Live/ Dead stain was applied directly to the surface of each sample. Next, $10 \mu \mathrm{L}$ of each primer were applied on the samples during $590 \mathrm{~s}$ for the real-time CLSM analysis. The experiment was conducted in triplicate. The primers and saline were also applied on the other dentin samples during 20,90, 300 and $590 \mathrm{~s}(\mathrm{n}=9$ for each group and period evaluated) and the CFU were assessed by colonies counting. Results: The results of the CLSM showed that with the SE application, although non-viable bacteria were detected at $20 \mathrm{~s}$, there was no increase in their count during $590 \mathrm{~s}$. In contrast, after the PB application there was a gradual increase of non-viable bacteria over $590 \mathrm{~s}$. Conclusions: The quantitative analysis demonstrated a significant decrease of S. mutans CFU at 90 s PB exposure and only after $300 \mathrm{~s}$ of SE application. Protect Bond showed an earlier antibacterial effect than SE Bond.

Key words: Biofilms. Streptococcus mutans. Dentin-bonding agents. Confocal microscopy. 


\section{INTRODUCTION}

The use of cavity disinfectants before restoration is an important clinical step because bacteria can remain in the smear layer or in the dentinal tubules, and can potentially multiply ${ }^{16}$. The ability of restorative materials to control bacteria by antimicrobial components is also desirable to help maintain residual microorganisms inactive ${ }^{14}$. The self-etching adhesive system, Clearfil Protect Bond, contains the antibacterial monomer 12-methacryloyloxydodecylpyridinium bromide (MDPB) in its primer. This monomer was incorporated to inactivate residual microorganisms on the dentin surface and to prevent bacterial invasion through the gap tooth/restoration?. MDPB monomer is a compound of the antibacterial agent quaternary ammonium and a methacryloyl group, which is covalently bound to the polymer matrix by its copolymerization with other monomers? MDPB has shown antimicrobial activity against oral streptococci, lactobacilli and microorganisms clinically isolated from root caries ${ }^{23}$. However, studies that evaluated the MDPB antibacterial effect were usually conducted in bacterial suspension and by agar diffusion testing $7,9,11$.

Since in the clinical practice adhesive systems are directly applied to the dentin with some level of contamination ${ }^{12,14,21}$, it would be crucial to evaluate the MDPB antibacterial effect against bacteria colonized on the dentin surface. This fact is also relevant because the bacteria adhered on the surfaces, forming biofilms, are less susceptible to antimicrobials than planktonic microorganisms (bacteria in suspension) ${ }^{4}$. However, few studies evaluated the antibacterial effect of adhesive systems containing MDPB against the biofilm ${ }^{10,15}$. Roland, et al. ${ }^{15}$ (2006) investigated the antibacterial effect of MDPB and fluoride on biofilm formation of dental adhesive surfaces to establish whether these components had the potential to reduce biofilm formation on adhesive system surfaces. It was found that the antibacterial agents within the resins have a minimal effect on biofilm formation ${ }^{15}$. Izutani, et al. ${ }^{10}$ (2011) evaluated the antibacterial effect of MDPB on S. mutans biofilm and showed that high concentrations of MDPB in solution are necessary to effectively kill biofilm S. mutans cells within an acceptable clinical time. Based on these results, it becomes necessary to evaluate if the application time of MDPB-containing a primer recommended by the manufacturer (20 s) is sufficient to decrease or eliminate microorganisms colonized on the dentin surface or for how long the bactericidal effect of MDPB-containing primer acts against these microorganisms.

Confocal laser scanning microscopy (CLSM) has been used to evaluate bacterial viability on dentin biofilms ${ }^{15}$. Fluorescence dyes are applied on the biofilm to differentiate live and dead bacteria, allowing bacteria to be distinguished according to cytoplasmic membrane permeability ${ }^{9}$. This holds particular relevance for studying the antimicrobial action of adhesive systems containing MDPB, because MDPB causes cell death through disruption of the cytoplasmic membrane ${ }^{7-9,15}$. Furthermore, CLSM can capture a series of image-scans showing changes in the viability of the bacterial cell over time, making the visualization of real-time death of microorganisms possible.

The aim of this study was to evaluate the bactericidal effect against $S$. mutans biofilm between self-etching priming solutions with and without MDPB (Clearfil Protect Bond and Clearfil SE Bond, respectively) over $590 \mathrm{~s}$ by real time CLSM analysis and count of viable bacteria test. The hypothesis tested in this study was that there is a difference in the bactericidal effect against $S$. mutans biofilm between primers with or without MDPB during $590 \mathrm{~s}$ by CLSM analysis and count of viable bacteria test.

\section{MATERIAL AND METHODS}

\section{Adhesive systems}

Two self-etching/priming solutions were tested, an antibacterial primer containing a MDPB monomer - Clearfil Protect Bond (Kuraray, Tokyo, Japan) - containing MDPB, MDP (10-methacryloxydecyldihydrogen phosphate), HEMA (2-hydroxyethylmethacrylate) and water, and a primer without an antibacterial monomer Clearfil SE Bond (Kuraray, Tokyo, Japan) - containing MDP, HEMA, dl-camphorquinone, N,N-diethanol-ptoluidine and water.

\section{Samples preparation}

One hundred fourteen bovine incisors were obtained and stored in $0.1 \%$ thymol solution. The buccal portion of the enamel was wet ground (Arotec, São Paulo, SP, Brazil) using 400 and 600 grit silicon carbide paper (Saint-Gobain, São Paulo, $\mathrm{SP}$, Brazil). Dentin samples with $4 \times 4 \mathrm{~mm}$ were obtained of each tooth using a low-speed diamond saw (Isomet, Buehler, Lake Bluff, IL, USA) and ground with 240 grit silicon carbide paper to reach $1.5 \mathrm{~mm}$ thickness. All samples were sterilized by steam autoclave (Phoenix, Araraquara, SP, Brazil) at $121^{\circ} \mathrm{C}$ for $15 \mathrm{~min}$.

\section{Bacterial colonization on the dentin}

S. mutans UA159 was used in this study. To prepare the inoculums, this microorganism strain was grown on Mitis salivarius agar plates at $37^{\circ} \mathrm{C}$ for $48 \mathrm{~h}$ in a $5 \%$ supplemented $\mathrm{CO}_{2}$ environment. Subsequently, single colonies were inoculated into $5 \mathrm{~mL}$ of $\mathrm{BHI}$ broth and incubated at $37^{\circ} \mathrm{C}$ for 24 
hrs. An overnight culture was adjusted to $1 \times 10^{6}$ [colony forming units $(\mathrm{CFU}) / \mathrm{mL}$ ] with an optical density of 0.6 at $600 \mathrm{~nm}$. The dentin surface of each sample was exposed to $20 \mu \mathrm{L}$ aliquot of $S$. mutans suspension in brain heart infusion broth (BHI) (Becton Dickinson, Sparks, MD, USA) without any disturbance, to allow for bacterial adherence. After 2 hrs at room temperature, the non-adhering cells were removed by washing three times with saline solution ${ }^{5}$. A sample was placed in each well of a 24-well multi-dish polystyrene plate (Nunclon, Thomas Scientific, Swedesboro, NJ, USA). Two $\mathrm{mL}$ of BHI broth supplemented with $1 \%(\mathrm{w} / \mathrm{v})$ sucrose (LabSynth, Diadema, SP, Brazil) were then added to the wells to simulate bacterial colonization ${ }^{5}$. The plates were incubated for $18 \mathrm{~h}$ at $37^{\circ} \mathrm{C}$ in a $5 \% \mathrm{CO}_{2}$ environment. The lack of contamination in the media of each well was verified using Gram staining and by plating the samples. The $18 \mathrm{~h}$ incubation period was established by a previous study, which verified that it was sufficient to develop a thin $S$. mutans biofilm (containing $10^{8}$ colony unit formation) without producing an intense demineralization of the dentin specimens, since the demineralization process could increase the dentin autofluorescence ${ }^{3}$ and harm the biofilm visualization by CLSM.

\section{Assessment of bactericidal effects by CLSM}

Live/Dead Baclight bacterial viability stain (L13152) (Molecular Probes, Eugene, OR, USA) was used in this study. It consists of a two nucleic acid-binding stains mixture: Syto 9 and propidium iodide. Syto 9 stains all viable bacteria in green, while propidium iodide stains in red the bacteria whose membranes were damaged (non-viable bacteria). Three samples were used for each solution application: Clearfil Protect Bond primer, Clearfil SE Bond primer and saline (control group). After 18 hrs of bacterial colonization, the non-adhering cells were removed by washing three times with saline solution ${ }^{5}$. Live/Dead was mixed according to the manufacturer's instructions and one drop was applied directly to the surface of each sample ${ }^{15}$. After 15 min in dark incubation ${ }^{5}$, the stain surplus was removed by absorbent paper and $10 \mu \mathrm{L}$ of each solution was applied on the samples' surface, according to each group. Immediately after, samples were analyzed by CLSM for 590 s (LSM510 META, Zeiss, Jena, Germany). This period was used based on the Imazato, et al. ${ }^{9}$ (2008) study, which found rapid killing of planktonic bacteria after contact with MDPB for 590 s. An excitation wavelength of 488 $\mathrm{nm}$ was used, and all light emitted between 500 $550 \mathrm{~nm}$ and over $560 \mathrm{~nm}$ was collected by different filters. The scan mode time series was used to take a series of time-lapse scans $(x y t)$ at intervals of 10 s during 590 s using continuous scanning with $10 x$ objective lens. Scans were taken in 8 bits at a resolution of 512 by 512 pixels. To standardize the gain and offset values to take a series scan, a preliminary sample prepared as described before was used. The experiment was conducted in triplicate.

\section{Assessment of bactericidal effects by viable bacteria count}

The primer application time was tested based on the CLSM results (20 s, 90 s, 300 s, 590 s). One-hundred eight dentin samples were used and twelve groups were obtained according to the time application of each primer or saline $(n=3)$ : saline application for 20 s, 90 s, 300 s and 590 s; Protect Bond application for $20 \mathrm{~s}, 90 \mathrm{~s}, 300 \mathrm{~s}$ and $590 \mathrm{~s}$ and SE Bond application for 20 s, 90 s, 300 s and $590 \mathrm{~s}$. The groups with the saline application were considered the negative control groups (no primer application). The experiment was repeated three times (triplicate). After $18 \mathrm{~h}$ of bacterial colonization as described before, $10 \mu \mathrm{L}$ of each primer or $0.9 \%$ $\mathrm{NaCl}$ solution was applied on the sample surface. The solutions were kept in contact with the $S$. mutans biofilm, without any disturbance for each group. The time was recorded by a chronometer. After each experimental time, the excess solutions were removed by sterile absorbent paper. Samples were immersed in individual Eppendorfs with $1 \mathrm{~mL}$ $0.9 \% \mathrm{NaCl}$ solution and sonicated for $30 \mathrm{~s}$ at $30 \%$ amplitude. The suspension was diluted in decimal series from $10^{-1}$ to $10^{-6}$ in $0.9 \% \mathrm{NaCl}$ solution and inoculated on $\mathrm{BHI}$ agar plates containing bacitracin $(2 \mathrm{U} / \mathrm{mL})^{13}$. The plates were incubated for $48 \mathrm{~h}$ at $37^{\circ} \mathrm{C}$ in a $5 \%$ supplemented $\mathrm{CO}_{2}$ environment and the number of viable bacteria (CFU) were assessed by counting the colonies formed. The data of CFU were submitted to the Kruskal-Wallis and Dunn's Multiple Comparisons tests at a significance level of $p<0.05$.

\section{RESULTS}

CLSM images showed $S$. mutans biofilm on the dentin surface with viable and non-viable colonies (green and yellow/red, respectively) and non-stained (black) bubble-like structures within the biofilm architecture (Figures 1, 2 and 3). The control group demonstrated viable bacteria during $590 \mathrm{~s}$, all colonies remained green, indicating that S. mutans were viable during the period evaluated (Figure 1). Non-viable bacteria (red colonies) were seen after the Clearfil SE Bond primer application (Figures $2 \mathrm{~A}$ and $2 \mathrm{~B}$ ), nonetheless, there was no increase of these bacteria during $590 \mathrm{~s}$ and viable bacteria were observed at this time (Figure 2C). After the Clearfil Protect Bond primer application some non-viable bacteria were visualized in $0 \mathrm{~s}$ (Figures $3 \mathrm{~A}$ and $3 \mathrm{~B}$ ). However, at $20 \mathrm{~s}$ (application 
time recommended by the manufacturer) viable bacteria was still visualized, and no difference was found between the viable and non-viable bacteria in $0 \mathrm{~s}$ and $20 \mathrm{~s}$ time-lapse scans (Figure 3A). The color change of $S$. mutans colonies to a yellowish or orange indicated the death of bacteria after the Clearfil Protect Bond primer application, (Figure 3A) showing a gradual increase of non-viable bacteria over 590 s. At 590 s, yellowish and red colonies were predominant (Figure $3 \mathrm{C}$ ).

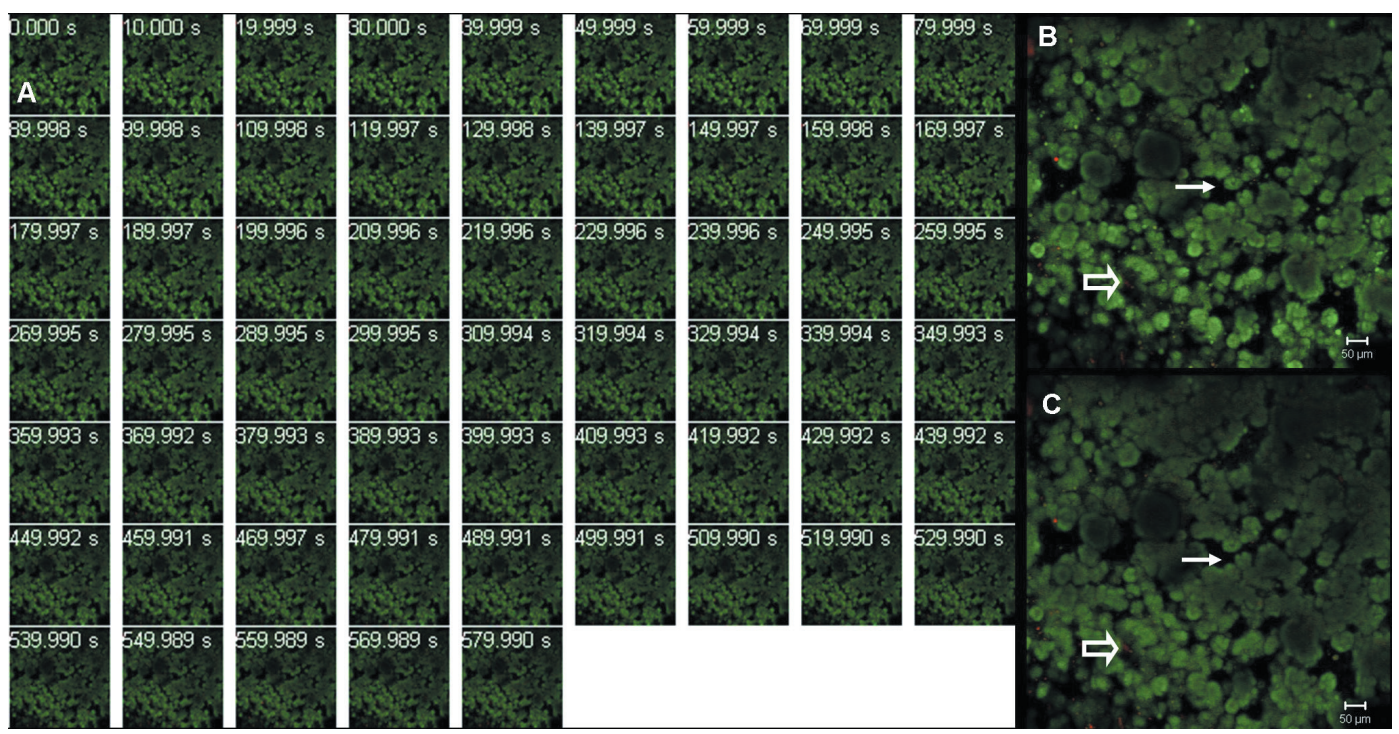

Figure 1- $S$. mutans biofilm on dentin surface after saline application (control group) visualized by confocal laser scanning microscopy (CLSM). Images were recorded in real-time over $590 \mathrm{~s}$. Viable bacteria are stained green and non-viable bacteria are stained yellowish/red color. Figure A shows image series of time-lapse scans according to the time (upper-left side of each scan). No bactericidal effect was observed because all colonies were stained green over 590 s. Figures B and $\mathrm{C}$ are higher magnification of image at zero time (Figure B) and at $590 \mathrm{~s}$ (Figure C), showing the presence of dead bacteria (open arrow) and non-stained (black) bubble-like structures within the biofilm architecture (arrow)

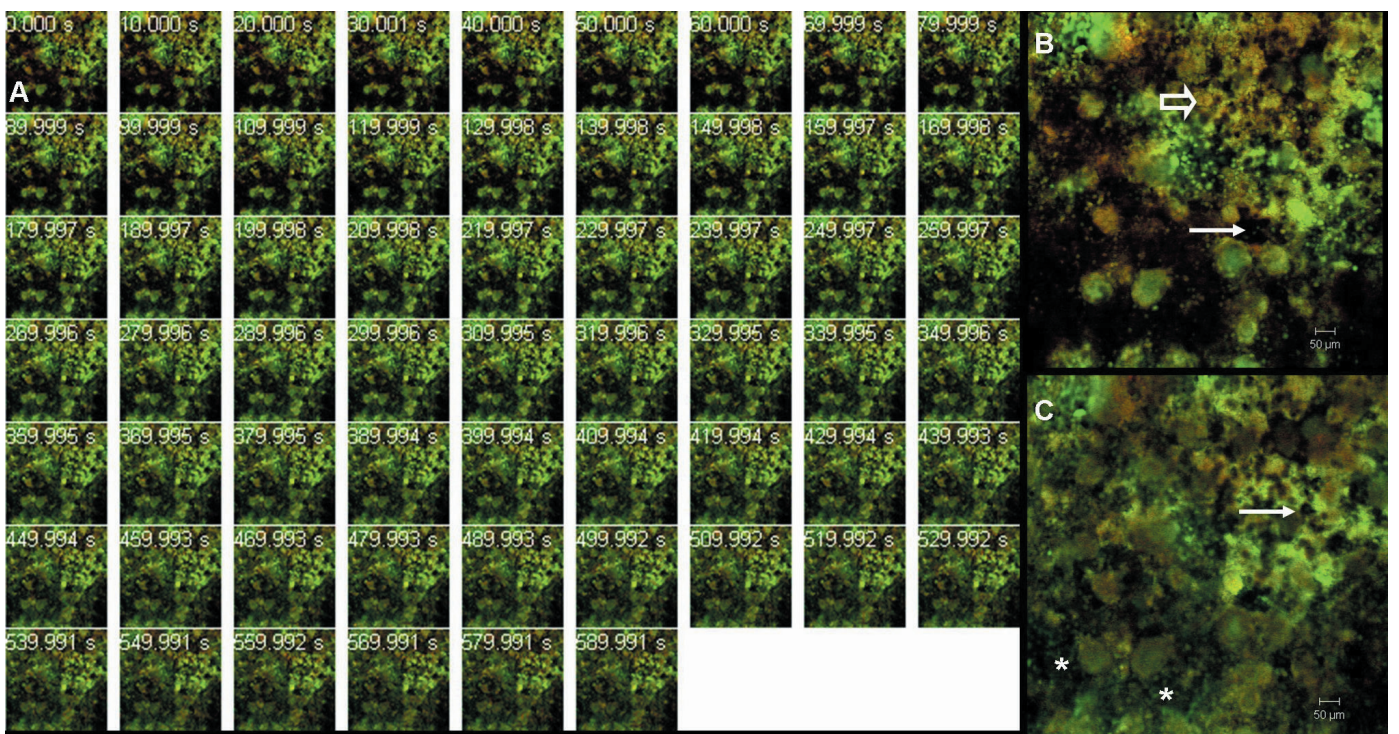

Figure 2- S. mutans biofilm on dentin surface after the Clearfil SE Bond primer application visualized by confocal laser scanning microscopy (CLSM). Images were recorded in real-time over $590 \mathrm{~s}$. Viable bacteria are stained green and nonviable bacteria are stained yellowish/red color. Figure A shows image series of time-lapse scans according to the time (upper-left side of each scan). Figures B and C are higher magnification of image at zero time (Figure B) and at $590 \mathrm{~s}$ (Figure C), showing the presence of dead bacteria (open arrow) and non-stained (black) bubble-like structures within the biofilm architecture (arrow). Non-viable bacteria (red colonies) were visualized after the Clearfil SE Bond primer application (Figures A and B), nonetheless, there was no increase of these bacteria during $590 \mathrm{~s}$ and viable bacteria were observed at this time (Figure C). *Low-intensity noise that can be attributed to the fluorescence of the primer 
Table 1 shows a quantitative analysis of the number of viable bacteria (CFU) of $S$. mutans biofilm on the dentin after the Clearfil Protect Bond, Clearfil SE Bond and saline application. There was no statistical difference among CFU after 20, 90, 300 and 590 s for the control and Clearfil SE Bond groups. In the contrary, the Clearfil Protect Bond group at $300 \mathrm{~s}$ and $590 \mathrm{~s}$ primer exposures showed a significant decreasing CFU compared to $20 \mathrm{~s}$.

When the comparisons were made among the primers and saline in each experimental time, at the initial time (20 s), no difference was found among the two primers and saline (Table 1). At $90 \mathrm{~s}$, the
Clearfil Protect Bond group showed a significant decreasing CFU compared to the control group and Clearfil SE Bond showed intermediate CFU between the control and Clearfil Protect Bond groups (Table 1). For the Clearfil SE Bond group the CFU decreased significantly after 300 s and 590 s of application, consequently the Clearfil Protect Bond showed an earlier antibacterial effect than the SE Bond (Table 1). At $300 \mathrm{~s}$ and $590 \mathrm{~s}$, both primers showed decreasing CFU compared to the control group, but with no difference between them (Table 1).
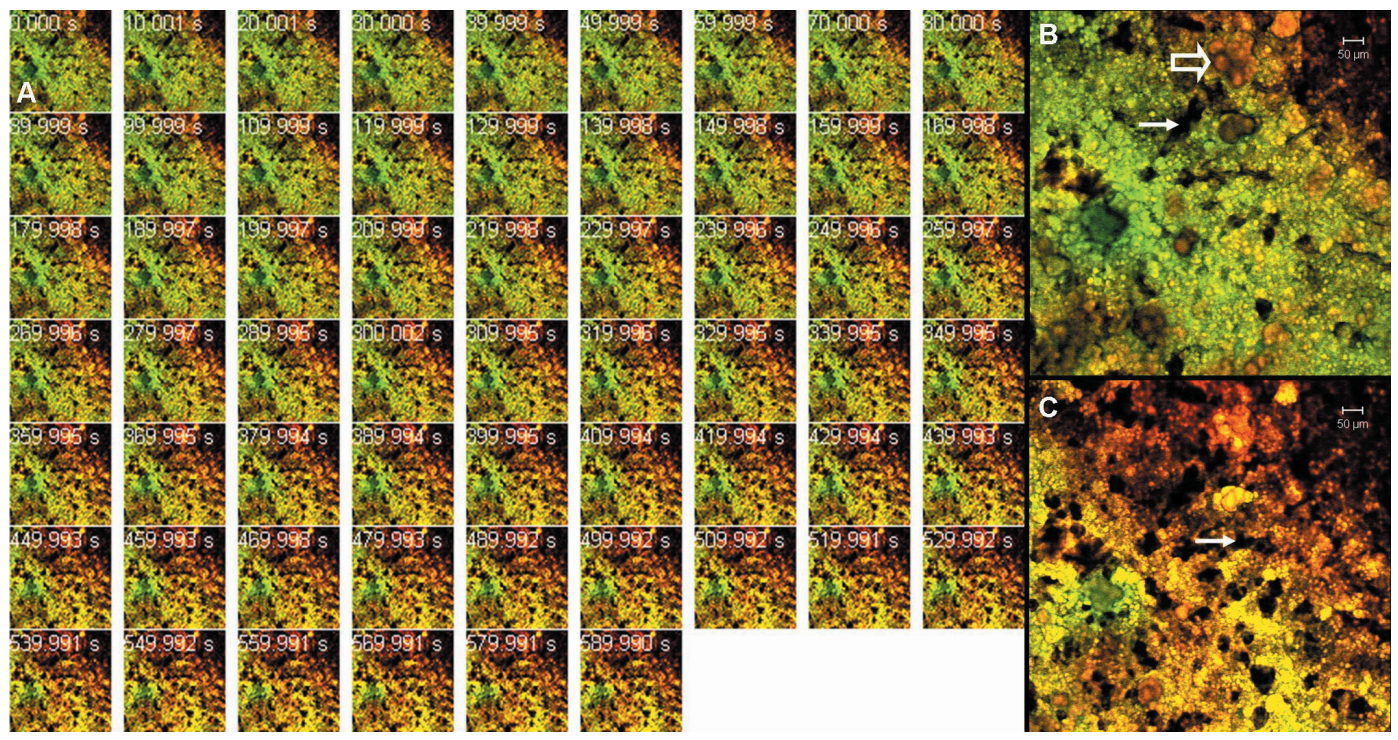

Figure 3- $S$. mutans biofilm on dentin surface after the Clearfil Protect Bond primer application visualized by confocal laser scanning microscopy (CLSM). Images were recorded in real-time over $590 \mathrm{~s}$. Viable bacteria are stained green and non-viable bacteria are stained yellowish/red color. Figure A shows image series of time-lapse scans according to the time (upper-left side of each scan). Figures B and C are higher magnification of image at zero time (Figure B) and at $590 \mathrm{~s}$ (Figure $\mathrm{C}$ ), showing the presence of dead bacteria (open arrow) and non-stained (black) bubble-like structures within the biofilm architecture (arrow). At $20 \mathrm{~s}$ (application time recommended by manufacturer) viable bacteria could be observed as in $0 \mathrm{~s}$ time-lapse scan (Figure A). A gradual increase of non-viable bacteria (yellowish/red colonies) could be observed over $590 \mathrm{~s}$ (Figure A), indicating the bactericidal effect of 12-methacryloyloxydodecylpyridinium (MDPB). Non-viable bacteria were predominant at $590 \mathrm{~s}$ (Figure C)

Table 1- Number of viable S. mutans (CFU) recovered after Clearfil Protect Bond and Clearfil SE Bond primer application at different times. Values are expressed in median (minimum/maximum)

\begin{tabular}{ccccc}
\hline Groups & $\mathbf{2 0 s}{ }^{*}$ & $90 \mathrm{~s}$ & $300 \mathrm{~s}$ & $590 \mathrm{~s}$ \\
\hline Control & $2.5 \times 10^{9 \mathrm{~A}, \mathrm{a}}$ & $1.0 \times 10^{9 \mathrm{~A}, \mathrm{a}}$ & $5.3 \times 10^{9 \mathrm{~A}, \mathrm{a}}$ & $2.5 \times 10^{9 \mathrm{~A}, \mathrm{a}}$ \\
& $\left(10^{4} / 10^{9}\right)$ & $\left(10^{8} / 10^{9}\right)$ & $\left(10^{8} / 10^{9}\right)$ & $\left(10^{8} / 10^{9}\right)$ \\
SE Bond & $9.0 \times 10^{4 \mathrm{~A}, \mathrm{a}}$ & $3.6 \times 10^{3 \mathrm{~A}, \mathrm{ab}}$ & $8.8 \times 10^{2 \mathrm{~A}, \mathrm{~b}}$ & $9.6 \times 10^{2 \mathrm{~A}, \mathrm{~b}}$ \\
& $\left(10^{4} / 10^{6}\right)$ & $\left(10^{3} / 10^{4}\right)$ & $\left(10^{2} / 10^{3}\right)$ & $\left(10^{2} / 10^{3}\right)$ \\
Protect Bond & $1.0 \times 10^{5 \mathrm{~A}, \mathrm{a}}$ & $1.0 \times 10^{3 \mathrm{AB}, \mathrm{b}}$ & $4.8 \times 10^{2 \mathrm{~B}, \mathrm{~b}}$ & $5.6 \times 10^{2 \mathrm{~B}, \mathrm{~b}}$ \\
& $\left(10^{4} / 10^{5}\right)$ & $\left(10^{2} / 10^{3}\right)$ & $\left(10 / 10^{2}\right)$ & $\left(10^{2} / 10^{3}\right)$ \\
\hline
\end{tabular}

\footnotetext{
* For each horizontal row: values with identical uppercase letters indicate no statistically significant difference $(P>0.05)$. For each vertical column: values with identical lowercase letters indicate no statistically significant difference $(P>0.05)$ according to Dunn's Multiple Comparisons test; $n=9$ for each time of each primer/saline application
} 


\section{DISCUSSION}

The null hypothesis was rejected because there was a difference in the bactericidal effect against S. mutans biofilm between self-etching priming solutions with and without MDPB by CLSM analysis and count of viable bacteria test. MDPB monomer can be considered a bactericidal agent against S. mutans biofilm, since it affected the bacteria membrane that could be detectable by fluorescent indicators.

Antimicrobial compounds that do not directly affect the cell membrane, such as those that interfere with protein or nucleic acid synthesis, are normally considered bacteriostatic and are not suitable agents to be studied by a viability staining method $^{1}$. Live/Dead Baclight has been shown to be an effective stain to distinguish viable and nonviable bacteria according to cytoplasmic membrane permeability ${ }^{2}$. As MDPB is a derivate of quaternary ammonium, it has a high affinity for negatively charged bacterial cells by a nitrogen atom on the pyridinium ring, which binds to the cell surface. The cell membrane loses its electrical balance, creating a disruption in the cytoplasmic membrane and the cell dies?.

Few studies evaluated the antibacterial effect of adhesive systems containing MDPB against the biofilm by CLSM analysis ${ }^{10,15}$. However, these earlier studies evaluated the effect of the MDPB monomer to reduce biofilm formation on the Clearfil Protect Bond adhesive system surface ${ }^{15}$ and the effect of high concentrations of unpolymerized MDPB solutions to kill $S$. mutans in planktonic or biofilm forms after 20, 40 or $60 \mathrm{~s}$ of contact $^{10}$. The primer containing-MDPB real-time effect against $S$. mutans biofilm by CLSM evaluation over $590 \mathrm{~s}$ had never been tested.

There was a good relation among the CFU results and the elapsed times of the CLSM analysis. The CLSM time-lapse scans and CFU results of the control group showed viable bacteria during $590 \mathrm{~s}$ (Figure 1 and Table 1). After the Clearfil SE primer application some non-viable bacteria were seen, however, the green staining was maintained in all periods tested (Figure 2). No statistical difference was found among the CFU during $590 \mathrm{~s}$ for the Clearfil SE Bond group (Table 1). The acidic nature of the primer of self-etching adhesive systems has been considered as one of the key factors related to bacterial inhibition ${ }^{6}$. The MDP monomer of Clearfil SE and Clearfil Protect Bond can have antibacterial activity because of its low pH level (1.9) $)^{6,18}$. However, the dentin can act as a buffer, because the acidic dissolution of the dentin apatite may be neutralized by the bonding between the dentin ions and $\mathrm{H}+$ ions of the monomer ${ }^{6}$. Consequently, the $\mathrm{pH}$ level of the MDP may have been neutralized by the buffering action of the dentin, leading to the visualization of viable bacteria by CLSM after the Clearfil SE primer application. Likewise, the MDP of the Clearfil SE Protect primer may also have been neutralized; however, the MDPB monomer showed a gradual bactericidal effect over 590 s and nonviable bacteria were predominant at $590 \mathrm{~s}$. The CFU results also showed a decrease after the 90, 300 and $590 \mathrm{~s}$ Clearfil Protect Bond application. These results confirmed previous studies that a MDPBcontaining primer has an antibacterial effect against S. mutans colonized in the dentin ${ }^{8,20}$.

Bacterial biofilms associated with surfaces are complex three-dimensional structures in which bacteria are embedded in a matrix mainly made of exopolysaccharides (EPS) ${ }^{19}$. EPS functions as an ion-exchange matrix and hinders the penetration of positively-charged antimicrobial agents ${ }^{17}$. The activation of an adaptive stress response and changes in gene and protein expression of bacteria are also factors that make biofilms 10 to 1000 times less sensitive to antimicrobial agents than planktonic bacteria ${ }^{1}$. Three main factors can be considered to the difference in susceptibility of planktonic and biofilm bacteria to antimicrobials ${ }^{10}$. One is the hindrance of penetration of antimicrobials into the biofilm, owing to the presence of a copious amount of an extracellular matrix, which acts as a molecular sieve. A second factor is that the chemical micro-environment, such as nutrientdepletion or waste products within the biofilm, may act as antagonists of antimicrobials. A third, and still speculative hypothesis is that some of the bacteria may differentiate into a protected phenotypic state ${ }^{10}$.

Some studies reported declining S. mutans counts in dentin chips and bacterial suspension after $20 \mathrm{~s}$ of the Clearfil Protect Bond primer application (application time recommended by the manufacturer $)^{7,8,11,20}$. However, the present study showed that there were viable bacteria at $20 \mathrm{~s}$ similar to $0 \mathrm{~s}$ time-lapse scan (Figure 1 ). Furthermore, the CFU results showed a decreasing number of bacteria after the $90 \mathrm{~s}$ Clearfil Protect Bond primer application (Table 1). Probably, the EPS among the biofilm channels may have impaired the penetration of MDPB and consequently its action, needing more time to kill bacteria since the mechanism of action for MDPB is based on the contact of immobilized antibacterial molecules with bacteria7. Thus, a gradual bactericidal effect was evidenced during the period evaluated. The results of the present study were contradictory to the Imazato, et al. ${ }^{9}$ (2008) results, which showed rapid killing of all bacteria (S. mutans) after 590 s contact with MDPB solution using Live/Dead Baclight bacterial viability stain and fluorescence microscopy, but the MDPB solution was tested 
against planktonic bacteria. Another study ${ }^{10}$ showed that high concentrations of MDPB are necessary to effectively kill planktonic and biofilm S. mutans cells within $60 \mathrm{~s}$ of contact, however, the biofilm produced under the experimental conditions of the Izutani, et al. ${ }^{10}$ (2011) study had a sparse structure (i.e. without a dense extracellular matrix) and this fact may have helped the penetration of MDPB and its antimicrobial effect ${ }^{10}$. The CLSM analysis showed a dense biofilm with some characteristics of in vivo biofilm (Figures 1, 2 and 3), such as the bubble-like structures and dead bacteria that were initially present. This dense structure of biofilm may also have impaired the antimicrobial effects of the Clearfil Protect Bond primer. The bubblelike structures were voids that were possibly filled with biological substances, such as EPS and glycoproteins, which are not stainable by the stain used $^{22}$. Besides, the dead bacteria might have been located in deeper regions of the biofilm and had reduced access to nutrients from the exposed medium $^{15}$.

The viability staining method provided a rapid and sensitive way to test the MDPB bactericidal effect against $S$. mutans biofilm. As the evidence of in vitro study must not be extrapolated to in vivo situations, clinical studies must be conducted to evaluate the application time of the Clearfil Protect Bond to disinfect the enamel/dentin cavity to obtain the antimicrobial activity. The collection of softened carious dentin or the use of swabs rubbed on to the base of the cavity before and after the primer application could be performed to clinically measure the antimicrobial activity ${ }^{14}$. Further investigations also need to be conducted against other cariogenic microorganisms in the biofilm or multispecies biofilm. Some attempts were made in this present study to test the MDPB effect after the bond application and cure, but the polymerized adhesive (bond) autofluorescence interfered with the bacteria visualization using CLSM.

\section{CONCLUSIONS}

Based on the findings of this study, and within the limitation of the in vitro investigation, it can be concluded that the Clearfil SE Bond primer presented a bactericidal effect only after $300 \mathrm{~s}$ against $S$. mutans biofilm and the Clearfil Protect Bond primer had a bactericidal effect against $S$. mutans biofilm after $90 \mathrm{~s}$ and showed a gradual bactericidal effect over 590 s by real-time CLSM evaluation and viable bacteria counting.

\section{ACKNOWLEDGEMENTS}

The authors are grateful to Dr. Toshie Kawano and Alexsander Souza of the Butantan Institute for their technical support for the CLSM analysis and the Kuraray Medical Company for supplying the materials. This study was supported by protocol \#05/57268-9 from FAPESP.

\section{REFERENCES}

1- Beckloff N, Laube D, Castro T, Furgang D, Park S, Perlin D, et al. Activity of an antimicrobial peptide mimetic against planktonic and biofilm cultures of oral pathogens. Antimicrob Agents Chemother. 2007;51:4125-32.

2- Berney M, Hammes F, Bosshard F, Weilenmann H, Egli T. Assessment and interpretation of bacterial viability by using the LIVE/DEAD BacLight kit in combination with flow cytometry. Appl Environ Microbiol. 2007;73:3283-90.

3- Carvalho FG, Fucio SB, Sinhoreti MA, Correr-Sobrinho L, PuppinRontani RM. Confocal laser scanning microscopic analysis of the depth of dentin caries-like lesions in primary and permanent teeth. Braz Dent J. 2008;19:139-44.

4- Chambless JD, Hunt SM, Stewart PS. A three-dimensional computer model of four hypothetical mechanisms protecting biofilms from antimicrobials. Appl Environ Microbiol. 2006;72:200513.

5- Fúcio SBP, Puppin-Rontani RM, Carvalho FG, Mattos-Graner RO, Correr-Sobrinho L, Garcia-Godoy F. Analyses of biofilms accumulated on dental restorative materials. Am J Dent. 2009;22:131-6.

6- Gondim JO, Duque C, Hebling J, Giro EM. Influence of human dentine on the antibacterial activity of self-etching adhesive systems against cariogenic bacteria. J Dent. 2008;36:241-8.

7- Imazato S, Kinomoto Y, Tarumi H, Torii M, Russell RRB, McCabe JF. Incorporation of antibacterial monomer MDPB into dentin primer. J Dent Res. 1997;76:768-72.

8- Imazato S, Kuramoto A, Takahashi Y, Ebisu S, Peters MC. In vitro antibacterial effects of the dentin primer of Clearfil Protect Bond. Dent Mater. 2006;22:527-32.

9- Imazato S, Ohmori K, Russell RR, McCabe JF, Momoi Y, Maeda $N$. Determination of bactericidal activity of antibacterial monomer MDPB by a viability staining method. Dent Mater J. 2008;27:145-8. 10- Izutani N, Imazato S, Nakajo K, Takahashi N, Takahashi $Y$, Ebisu S, et al. Effects of the antibacterial monomer 12-methacryloyloxydodecylpyridinium bromide (MDPB) on bacterial viability and metabolism. Eur J Oral Sci. 2011;119:17581.

11- Korkmaz Y, Ozalp M, Attar N. Comparison of the antibacterial activity of different self-etching primers and adhesives. J Contemp Dent Pract. 2008;9:57-64.

12- Lima GQ, Oliveira EG, Souza JI, Monteiro Neto V. Comparison of the efficiency of chemomechanical and mechanical methods of caries removal in the reduction of Streptococcus mutans and Lactobacillus spp in carious dentine of primary teeth. J Appl Oral Sci. 2005;13:399-405.

13- Mikami Y, Suzuki N, Takahashi T, Otsuka K, Tsuda H. Bacitracin upregulates mbrAB transcription via mbrCD to confer bacitracin resistance in Streptococcus mutans. J Pharmacol Sci. 2011;117:204-7.

14- Neelakantan P, Rao CVS, Indramohan J. Bacteriology of deep carious lesions underneath amalgam restorations with different pulp-capping materials: an in vivo analysis. J Appl Oral Sci. 2012;20:139-45.

15- Rolland SL, McCabe JF, Robinson C, Walls AW. In vitro biofilm formation on the surface of resin-based dentine adhesives. Eur J Oral Sci. 2006;114: 243-9. 
16- Silva NR, Calamia CS, Coelho PG, Carrilho MR, Carvalho RM, Caufield $P$, et al. Effect of $2 \%$ iodine disinfecting solution on bond strength to dentin. J Appl Oral Sci. 2006;14:399-404.

17- Stewart PS. Diffusion in biofilms. J Bacteriol. 2003;185:148591.

18- Susin AH, Alves LS, Melo GP, Lenzi TL. Comparative scanning electron microscopic study of the effect of different dental conditioners on dentin micromorphology. J Appl Oral Sci. 2008; 16:100-5.

19- Ten Cate JM. Biofilms, a new approach to the microbiology of dental plaque. Odontology. 2006;94:1-9.

20- Türkün M, Türkün LS, Ergücü $Z$, Ateş M. Is an antibacterial adhesive system more effective than cavity disinfectants? Am J Dent. 2006;19:166-70.
21- Wambier DS, Santos FA, Guedes-Pinto AC, Jaeger RG, Simionato MRL. Ultrastructral and microbiological analysis of dentin layers affected by caries lesions in primary molars treated by minimal intervention. Ped Dent. 2007;29:228-34.

22- Wood SR, Kirkham J, Marsh PD, Shore RC, Nattress B, Robinson C. Architecture of intact natural human plaque biofilms studied by confocal laser scanning microscopy. J Dent Res. 2000;79:21-7. 23- Yoshikawa K, Clark DT, Brailsford SR, Beighton D, Watson TF, Imazato $\mathrm{S}$, et al. The effect of antibacterial MDPB monomer on the growth of organisms associated with root caries. Dent Mater J. $2007 ; 26: 388-92$. 